\title{
Accumulation of long chain fatty acids onto anaerobic sludge under steady state and shock loading conditions: effect on acetogenic and methanogenic activity
}

\author{
M.A. Pereira, A.J. Cavaleiro, M. Mota and M.M. Alves \\ Centro de Engenharia Biológica, Universidade do Minho, 4710-057 Braga Portugal \\ (E-mail: Madalena.alves@deb.uminho.pt)
}

\begin{abstract}
Accumulation of substrate onto the biomass was quantified under steady-state and shock conditions in a fixed bed reactor fed with an oleic acid-based synthetic effluent. The accumulation of substrate onto the sludge was more dependent on oleic acid concentration than on oleic acid loading rate and decreased the acetogenic, acetoclastic and hydrogenophilic activity. However, even when the methanogenic activity measurements indicate a severe inhibition, the anaerobic sludge was able to methanise efficiently the accumulated substrate that was mainly adsorbed LCFA. Methanogenic activity measurements for a sludge loaded with $2,861 \mathrm{mg} \mathrm{COD/gVSS}$ as LCFA, revealed that only hydrogenophilic activity was detetcted, whereas the methanogenic activities with acetate, propionate and butyrate as substrates were null. However the methanogenic activity of the same sludge after allowing the depletion of the adsorbed LCFA were significantly enhanced in the presence of all substrates, except in propionate. A discussion about the relative importance of metabolic inhibition and transport limitations for the anaerobic degradation of LCFA is launched.
\end{abstract}

Keywords Adsorption; long chain fatty acids; methanogenic activity

\section{Introduction}

If compared with other organic matter, lipids are attractive for biogas production due to their high theoretical methane production. However, application of continuous anaerobic digesters to lipid-containing wastewaters is reported to be hindered by the acute toxicity of Long Chain Fatty Acids (LCFA) towards the anaerobic consortium and by the adsorption of these compounds onto the biomass, inducing sludge flotation and washout (Hanaki et al., 1981; Rinzema et al., 1994; Hwu et al., 1998). In spite of these problems, effective methanisation of high loads of LCFA is possible. In a previous study, when operating an EGSB reactor continuously up to $6 \mathrm{~kg}$ oleate $\mathrm{COD} / \mathrm{m}^{3} . \mathrm{d}$, as the sole carbon source, the methane yield was as low as $27 \mathrm{CCH}_{4} / \mathrm{kg} \mathrm{COD}$ removed , less than $10 \%$ of the theoretical value. When samples of biomass were taken from the reactor, washed and incubated in batch assays without any added carbon source, effective methanisation of the accumulated substrate was observed, achieving a maximum plateau of $1,145 \pm 307 \mathrm{ml} \mathrm{CH}_{4} / \mathrm{g}$ VSS $(3,271 \mathrm{mg}$ COD-CH $/ \mathrm{gVSS})$ at a specific production rate of $85 \pm 3 \mathrm{ml} \mathrm{CH}_{4} / \mathrm{gVSS}$.d (243 mg COD-CH $\mathrm{CH}_{4} / \mathrm{gVSS} . \mathrm{d}$ ) (Pereira et al., 2002). This procedure allowed the quantification of biomass - associated LCFA, which was considered to be mainly, adsorbed LCFA. Although only oleic acid was fed to the reactors, the use of the term "adsorbed LCFA" was considered more appropriate, since an extraction and GC analysis of this adsorbed matter revealed that it was composed by intermediates of oleate degradation, mainly palmitic acid.

In the present work, the same methodology was used to quantify the accumulation of substrate onto the sludge of a fixed bed reactor fed with an oleic acid-based synthetic effluent, under steady-state and shock loading conditions. The same sludge samples were also characterised for the methanogenic activities with acetate, propionate, butyrate and $\mathrm{H}_{2} / \mathrm{CO}_{2}$ as substrates. The aim is to establish a direct relationship between the amount of 
accumulated substrate and the methanogenic activities on the different substrates as a new way to represent the toxicity of these compounds. The term "accumulated substrate" was considered in this work to represent the biomass-associated substrate which can be residual substrate, adsorbed substrate and/or precipitated substrate.

\section{Methods}

\section{Experimental set-up}

A fixed bed reactor was constructed in PVC with a total volume of 86.8 litres and a diameter of $48 \mathrm{~cm}$. The support medium was equally divided among 27 parallel mini-bioreactors arranged in the central section, which aimed to simulate the behaviour of the support matrix in an anaerobic filter. Each mini-bioreactor had $7.1 \mathrm{~cm}$ internal diameter, a total volume of $989 \mathrm{~cm}^{3}$ and accommodated 89 pieces of support material. The support medium consisted of PVC Raschig rings of $21 \mathrm{~mm}$ size, with a specific surface area of $230 \mathrm{~m}^{2} / \mathrm{m}^{3}$ and a porosity of $92.5 \%$. This reactor configuration was described in detail elsewhere (Alves $e t$ $a l ., 1998)$ and allowed the sampling of biomass during the operation. Operating temperature was kept constant at $35 \pm 1{ }^{\circ} \mathrm{C}$ and routine reactor performance was monitored by determining influent and effluent total and soluble Chemical Oxygen Demand (COD), influent flow rate and effluent volatile fatty acids (VFA).

\section{Operation mode}

During the steady-state operation, which lasted 426 days, the seed sludge consisted of 11 litres of sludge ( $25.7 \mathrm{~g}$ of volatile solids (VS) per litre) and was obtained from a municipal sludge digester. Table 1 presents the operating conditions prevailing at the moment of biomass withdrawal. The reactor was opened at six different operation times and 3 of the 27 mini-bioreactors were randomly selected and replaced by new similar mini-bioreactors, which were not accounted for in the next selection.

The same reactor was used to perform two shock loading experiments (one organic and one hydraulic). The reactor was inoculated with $15 \mathrm{l}$ of seed sludge containing $10 \mathrm{~g}$ of volatile suspended solids (VSS) per litre, which was obtained from a local municipal sludge anaerobic digester. Table 2 summarises the operating conditions applied. During the startup (Period I) the applied organic loading rate was gradually raised up to $6 \mathrm{~kg} \mathrm{COD} / \mathrm{m}^{3} . \mathrm{d}$.

The reactor was initially fed with skim milk followed by a mixture of skim milk $(50 \%$ COD) and sodium oleate (50\% COD). This proportion remained constant during all subsequent operation periods. After the start-up, the applied organic loading rate was increased 5-fold (30 kg COD $/ \mathrm{m}^{3} . \mathrm{d}$ ), by increasing the substrate concentration (simulation of an organic shock - Period II) or by decreasing the hydraulic retention time, HRT (simulation of a hydraulic shock - Period III). Both shocks lasted 4 days after which there was a return to pre-shock conditions (Table 2). At different moments during the shocks, the reactor was opened and 2 of the mini-bioreactors, randomly selected, were removed and replaced by

Table 1 Operating conditions prevailing at the moment of biomass characterization (adapted from Alves et al., 2001)

\begin{tabular}{lccclc}
\hline Period & Time (d) & Influent COD (mg/l) & HRT (d) & Type of substrate & Organic loading (kg CoD/m $\mathbf{~}^{\mathbf{. d})}$ \\
\hline & 90 & 3,000 & 0.9 & Skim milk (100\% COD) & 3.33 \\
I & 132 & 6,000 & 1.4 & Skim milk (100\% COD) & 4.29 \\
& 162 & 9,000 & 1.4 & Skim milk (100\% COD) & 6.43 \\
II & 212 & 12,000 & 1.4 & Skim milk (100\% COD) & 8.57 \\
& 315 & 12,000 & 1.4 & Skim milk (50\% COD) & 8.57 \\
III & 426 & 12,000 & 1.4 & Sodium oleate (50\% COD) & 8.57 \\
\hline
\end{tabular}


Table 2 Operating conditions during the trial period (adapted from Cavaleiro et al., 2001)

\begin{tabular}{|c|c|c|c|c|c|c|}
\hline Period & Time (d) & $\begin{array}{l}\text { Influent } \\
\operatorname{COD}(\mathrm{mg} / \mathrm{l})\end{array}$ & HRT (d) & Type of substrate & $\begin{array}{r}\text { Organic loading } \\
\left(\mathrm{kg} \mathrm{COD} / \mathrm{m}^{3} \cdot \mathrm{d}\right)\end{array}$ & Remarks \\
\hline & $0-16$ & 2,000 & 4 & Skim milk & 0.5 & \\
\hline & $16-34$ & 2,000 & 2 & Skim milk & 1 & \\
\hline \multirow[t]{4}{*}{ I } & $34-54$ & 4,000 & 2 & Skim milk & 2 & \\
\hline & $54-83$ & 4,000 & 1 & Skim milk & 4 & \\
\hline & 83-102 & 4,000 & 1 & $\begin{array}{c}\text { Skim milk (50\% COD) + } \\
\text { sodium oleate (50\% COD) }\end{array}$ & 4 & $\begin{array}{l}\text { Introduction } \\
\text { of oleate }\end{array}$ \\
\hline & $102-140$ & 4,000 & 0.667 & $\begin{array}{l}\text { Skim milk ( } 50 \% \text { COD) + } \\
\text { sodium oleate (50\% COD) }\end{array}$ & 6 & $\begin{array}{l}\text { Pre-shock } \\
\text { conditions }\end{array}$ \\
\hline \multirow[t]{2}{*}{ II } & $140-144$ & 20,000 & 0.667 & $\begin{array}{l}\text { Skim milk (50\% COD) + } \\
\text { sodium oleate (50\% COD) }\end{array}$ & 30 & Organic shock \\
\hline & $144-230$ & 4,000 & 0.667 & $\begin{array}{c}\text { Skim milk ( } 50 \% \text { COD) } \\
+ \text { sodium oleate }(50 \% \text { COD }\end{array}$ & 30 & $\begin{array}{l}\text { Organic shock } \\
\text { conditions }\end{array}$ \\
\hline \multirow[t]{2}{*}{ III } & $230-234$ & 4,000 & 0.133 & $\begin{array}{l}\text { Skim milk }(50 \% \text { COD })+ \\
\text { sodium oleate }(50 \% \text { COD) }\end{array}$ & 30 & Hydraulic shock \\
\hline & $234-286$ & 4,000 & 0.667 & $\begin{array}{l}\text { Skim milk (50\% COD) + } \\
\text { sodium oleate (50\% COD) }\end{array}$ & 30 & $\begin{array}{l}\text { Hydraulic shock } \\
\text { conditions }\end{array}$ \\
\hline
\end{tabular}

new similar ones, which were not accounted for in the next selection. The substrate was diluted with tap water, and supplemented with macro and micronutrients as described elsewhere (Alves et al., 2001). To give suitable alkalinity, $5 \mathrm{~g} \mathrm{NaHCO}_{3}$ were added per litre of feed.

\section{Biomass characterisation}

Quantification of the accumulated substrate. All the sludge samples collected were washed and centrifuged twice with anaerobic basal medium and incubated in batch vials of $25 \mathrm{ml}$ at $37^{\circ} \mathrm{C}, 150 \mathrm{rpm}$ under strict anaerobic conditions, without any added substrate. The methane production was followed by measuring the pressure developed in each vial, using a hand held pressure transducer capable of measuring a pressure variation of two bar ( 0 to \pm 202.6 $\mathrm{kPa}$ ) over an output range of -200 to $+200 \mathrm{mv}$ (Colleran et al., 1992). The basal medium used in all the batch experiments was made up with demineralised water, was composed of cysteine-HCL $(0.5 \mathrm{~g} / \mathrm{l})$ and sodium bicarbonate $(3 \mathrm{~g} / \mathrm{l})$, the $\mathrm{pH}$ was adjusted to $7.0-7.2$ with $\mathrm{NaOH} 8 \mathrm{~mol} \mathrm{l}^{-1}$ and was prepared under strict anaerobic conditions. No calcium or tracenutrients were added. Methane content of the biogas was measured by gas chromatography using a Chrompack Haysep Q (80 to $100 \mathrm{mesh}$ ) column, with $\mathrm{N}_{2}$ carrier gas at $30 \mathrm{ml} / \mathrm{min}$ and a flame-ionization detector. Temperatures of the injection port, column, and flame-ionization detector were 120,40 , and $130^{\circ} \mathrm{C}$, respectively. The values of methane production were corrected for the standard temperature and pressure conditions (STP). The methane production rate and the maximum plateau achieved were determined for each vial. The maximum plateau was considered an indirect measurement of the amount of accumulated substrate (biomass-associated substrate). Specific methane production rate from this substrate was obtained by dividing the initial slope of each curve of methane production by the VSS content of each vial at the end of the experiment and were expressed as mg COD$\mathrm{CH}_{4} / \mathrm{gVSS}$.d. The amount of adsorbed substrate per VSS unit was determined by dividing the maximum plateau achieved in the methane production curve by the VSS content of each vial at the end of the experiment and were expressed as $\mathrm{mg} \mathrm{COD}-\mathrm{CH}_{4} / \mathrm{gVSS}$ (Figure 1).

Methanogenic activity measurements. The same biomass samples were also characterised in terms of specific methanogenic activity using the above referred pressure transducer technique. The pressure increase developed in the batch vials fed with non gaseous 


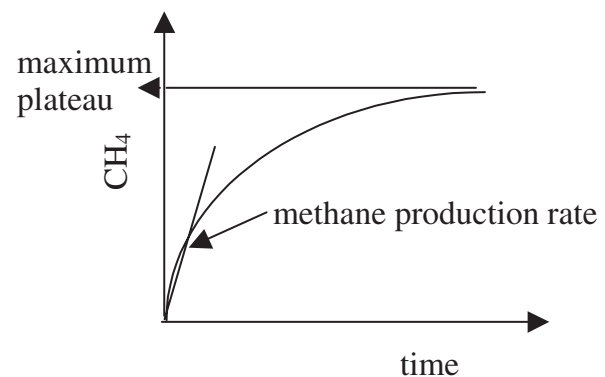

Figure 1 Example of a curve obtained in the batch assays

substrates (30 mM acetate, $30 \mathrm{mmol} \mathrm{l}^{-1}$ propionate and $15 \mathrm{mmol}^{-1}$ butyrate) or pressure decrease in vials previously pressurized ( 1 bar) with gaseous substrates $\left(\mathrm{H}_{2} / \mathrm{CO}_{2}-80: 20\right.$ $\mathrm{vol} / \mathrm{vol}$ ) was monitored. Blank controls were used for liquid substrates (no added substrate) and for gaseous substrates (pressurized with $\mathrm{N}_{2} / \mathrm{CO}_{2}-80: 20 \mathrm{vol} / \mathrm{vol}$ at $1 \mathrm{Bar}$ ). All the batch experiments were performed in triplicate assays. Specific methanogenic activity values were determined dividing the initial slope of the methane production curve by the VSS content of each vial at the end of the experiment. Background methane production due to the residual/adsorbed/precipitated substrate was discounted.

\section{Results and discussion}

Figure 2 represents the accumulation of substrate onto the biomass under steady-state (Figure 2a) and shock loading conditions (Figure 2b). During the steady-state operation, the accumulated substrate remained constant around $400 \mathrm{mg} \mathrm{COD}-\mathrm{CH}_{4} / \mathrm{gVSS}$, except in the period III (oleate as sole carbon source), when a significant increase was found, attaining a maximum value of $1,874 \pm 51 \mathrm{mgCOD}-\mathrm{CH}_{4} / \mathrm{gVSS}$. During the Period I the accumulated substrate should represent residual substrate, since the feed to the reactor was composed exclusively of skim milk, which has not adsorbable compounds. It is not expected that adsorption occurred significantly during this Period. In Period II oleate was fed as $50 \%$ of the total COD and in Period III, oleate was the sole carbon source fed to the reactor. In these Periods, it is expected that accumulated substrate represents mainly adsorbed LCFA, although some precipitated LCFA can also be present. The relative importance of LCFA adsorption in the process of substrate accumulation was particularly evident when oleate was the sole carbon source fed to the reactors (Period III), since the accumulated substrate increased significantly and the sludge exhibited a whitish and greasy appearance.

Under shock conditions oleate represented 50\% COD fed to the reactors. In both shocks a steady increase of substrate accumulated (mainly adsorbed LCFA) onto the sludge was observed during the shock time followed by a return to the pre-shock values during the post-shock recovery time. This increase was significantly higher in the organic than in the hydraulic shock, achieving maximum values of $927 \pm 52$ and $525 \pm 11 \mathrm{mg}$ COD$\mathrm{CH}_{4} / \mathrm{gVSS}$, respectively. This clearly shows that under continuous operation, the accumulation of substrate onto the sludge depended more on oleic acid concentration than on oleic acid volumetric loading rate. The accumulated substrate is the net result from the balance between adsorption/precipitation and degradation phenomena that occur simultaneously in the reactor. In the hydraulic shock, besides the much lower bulk oleate concentration that reduces the driving force of adsorption, the higher shear stress could have enhanced the biogas release inducing a more efficient degradation. This effect was also observed in a previous study (Pereira et al., 2001).

Figure 3 shows the influence of the accumulated substrate on its own degradation rate to methane. 

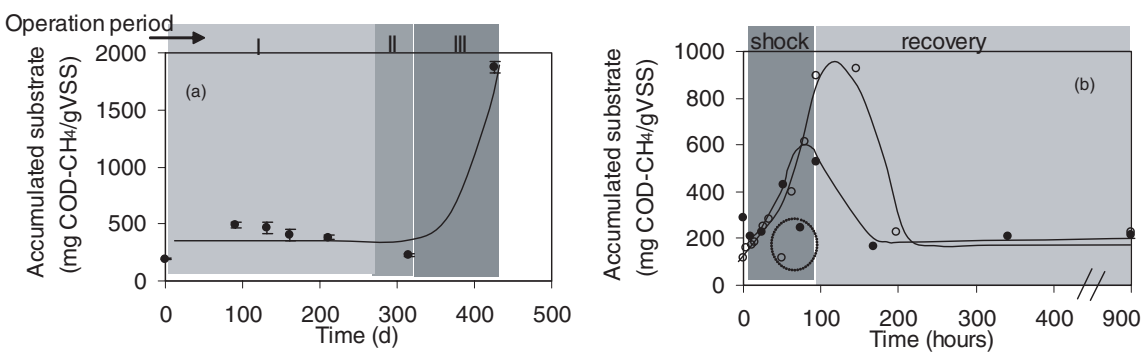

Figure 2 Accumulation of substrate under steady-state (a) and shock loading (b) conditions
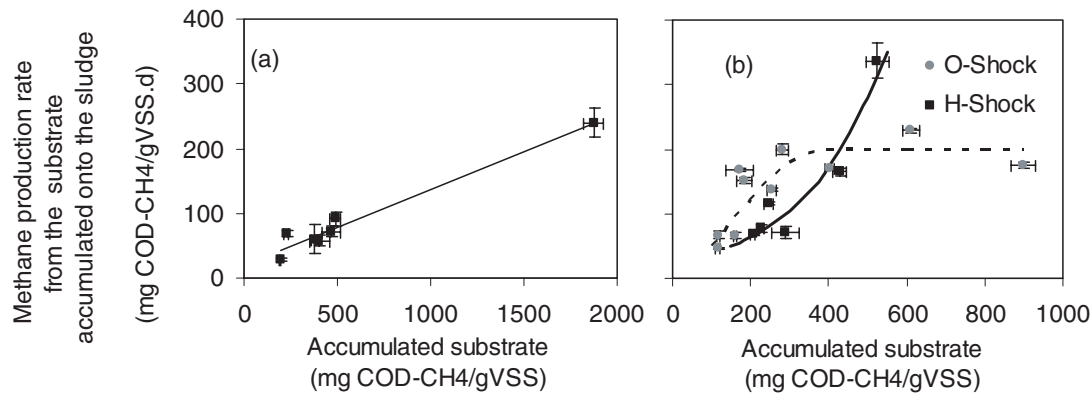

Figure 3 Methane production rate due to the degradation of the accumulated (biomass-associated) substrate exhibited by the sludge samples collected under steady-state (a) and shock loading (b) conditions

It is interesting to observe the capacity of the sludge to methanize the accumulated substrate, clearly demonstrating that anaerobic consortia are active even when the sludge is loaded with amounts of adsorbed LCFA, up to 2,000 $\mathrm{mg}$ COD/gVSS. The occurrence of LCFA adsorption is reported in the literature (Rinzema et al., 1994; Hwu et al., 1998), but quantification of this phenomenon is not documented. The methodology presented by Pereira et al. (2002) and used also in this work, allowed the quantification of the amount of substrate accumulated onto the sludge. In general, when oleic acid was introduced in the feed, the accumulated substrate increased significantly, due to LCFA adsorption. In those cases, accumulated substrate can be redefined as adsorbed LCFA.

The quantification of adsorbed LCFA for the sludge samples that were also characterized in terms of specific methanogenic activity on different individual substrates, allowed the establishment of a direct relationship between the amount of adsorbed LCFA and the acetoclastic, acetogenic and hydrogenophilic activities (Figure 4). Under steady-state conditions, the sludge samples taken during the Period I were not considered, because the substrate fed was not based on LCFA. A clear decreasing trend between all activities and the accumulated LCFA was observed, more significant for the acetogenic (Figure 4 (b) and (c)) than for the acetoclastic or hydrogenophilic activities (Figure 4 (a) and (d)).

Toxicity measurements are usually performed by adding increasing concentrations of a toxic to different vials simultaneously with a constant concentration of the specific substrate that is consumed by the trophic group under study. Ideally a constant toxic concentration should be present in the bulk medium while the specific substrate is consumed. When this method is applied for an adsorbable and biodegradable substrate such as oleic acid, the toxic concentration in the medium may change before and/or during the consumption of the substrate, due to adsorption onto the sludge and/or to biodegradation. The direct relationship between the amount of adsorbed LCFA and the methanogenic activities on the different substrates (Figure 4) may be a more representative way to express the toxicity of these compounds, since the adsorption of LCFA is an important and well reported phenomenon. Observing Figure 4, it is possible to estimate the values of adsorbed LCFA per sludge 

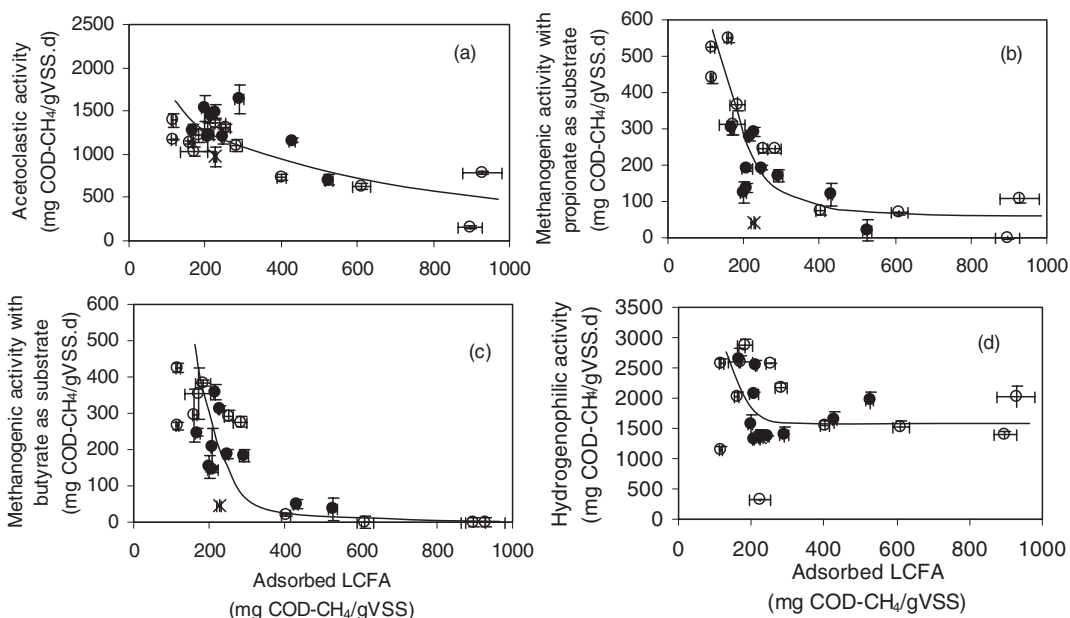

Figure 4 Effect of adsorbed LCFA on the specific methanogenic activity with acetate (a), propionate (b), butyrate (c) and $\mathrm{H}_{2} / \mathrm{CO}_{2}$ (d) as substrates. Biomass samples taken under steady-state (*), hydraulic $\operatorname{shock}(\mathbf{)})$ and organic shock $(O)$ conditions

unit that reduces the activities to $50 \%$ of the maximum detected, these values being about 500 and $200 \mathrm{mg} \mathrm{COD} / \mathrm{gVSS}$, for the acetoclastic and the acetogenic activity (on propionate and butyrate), respectively. For the hydrogenophilic activity the value is not defined, since the $50 \%$ reduction is maintained in the range between 200 and 1,000 $\mathrm{mg} \mathrm{COD/gVSS}$. Although the methanogenic activity seemed to be severely inhibited by the adsorbed LCFA it is unlikely that acetogenic and methanogenic populations were killed due to the bactericidal effect of these compounds, as suggested by Rinzema et al. (1994), since the biomass was able to produce methane exclusively from the adsorbed substrate, as shown in Figure 3 (a) and (b). This was confirmed by the results presented in Figure 5. Methanogenic activity measurements for a sludge loaded with $2861 \mathrm{mg}$ COD/gVSS as LCFA are presented in Figure 5 (a). This sludge was taken from an EGSB reactor fed with oleic acid as the sole carbon source at an influent concentration of $4 \mathrm{~g}$ COD/L and an HRT of 1 day. The hydrogenophilic activity was detected, but the methanogenic activities with acetate, propionate and butyrate as substrates were null, because the methane production rate from the adsorbed LCFA (blank control) was higher than that observed with the tested substrates. However, after allowing the depletion of the adsorbed LCFA the methanogenic activities of the same sludge, in the presence of all substrates, were significantly enhanced, with the single exception of the methanogenic activity with propionate as substrate (Figure $5(b))$.
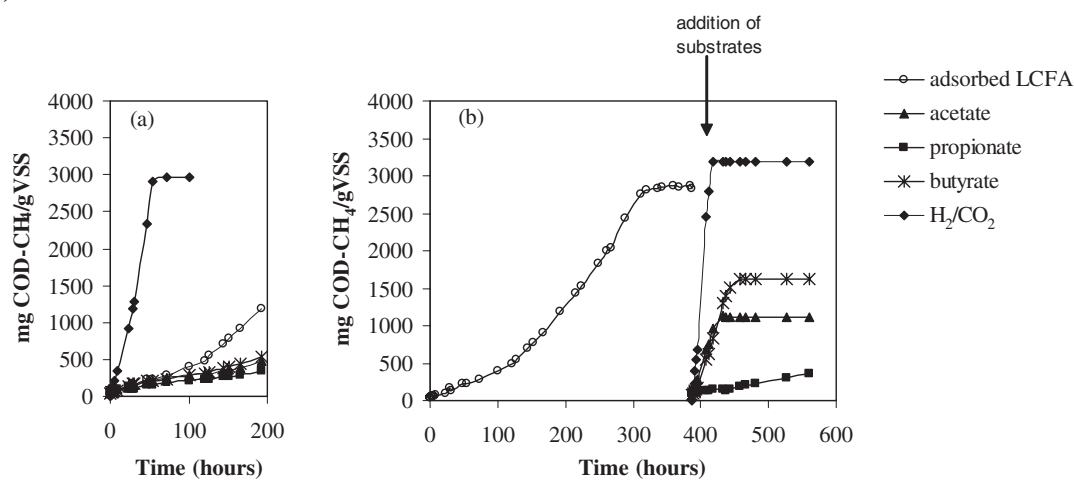

Figure 5 Methanogenic activity before (a) and after (b) the depletion of the adsorbed LCFA 
These results clearly show that, after degrading the adsorbed LCFA, the methanogenic activity was enhanced, contradicting the well reported and accepted theories of the bactericidal and permanent toxic effect of LCFA towards anaerobic bacteria reported by Rinzema et al. (1994) and by Angelidaki and Ahring (1992), respectively.

Although it is proven that the toxic effect of adsorbed LCFA is not permanent, it is not completely clear from these results whether there is or is not a transitory metabolic inhibition when the LCFA are adsorbed to the sludge. In fact, the null activities measured for the loaded (encapsulated with LCFA) sludge can represent simply a delay in methane production due to transport limitation effects. Transport of substrates form the bulk liquid to the cells can be hindered by the adsorbed layer of LCFA, this step being overcome when the substrate is already in intimate contact with the cells (as in the case of adsorbed substrate). This hypothesis is reinforced by the fact that $\mathrm{H}_{2}$, the smallest substrate tested, was immediately transformed into methane, suggesting that its diffusion through the LCFA layer was faster than for the other substrates. The differentiation between a transitory toxic effect and a transport limitation effect needs to be investigated. Probably both phenomena are involved, since, for instance, the methanogenic activity with propionate as substrate did not increase after the depletion of the adsorbed LCFA, suggesting that this particular trophic group can be affected. However, to be sure about that, the long term history of the sludge should be considered. In this case, the sludge used in the experiment presented in Figure 5 was taken from a continuous reactor fed with oleic acid and the inoculum of this reactor exhibited already a null methanogenic activity with propionate as substrate.

\section{Conclusions}

Substrate accumulated onto the sludge of a fixed bed reactor fed with an oleic acid-based synthetic effluent under steady-state and shock loading conditions, was more dependent on oleic acid concentration than on oleic acid loading rate. Acetogenic, acetoclastic and hydrogenophilic activities decreased when the amount of adsorbed LCFA increased. This effect was more severe for the methanogenic activity in the presence of propionate and butyrate than for the acetoclastic activity. The hydrogenophilic activity remained at a constant value of about $1,500 \mathrm{mg} \mathrm{COD}-\mathrm{CH}_{4} / \mathrm{gVSS}$.d, for the range of adsorbed LCFA between 200 and 1,000 mg COD/gVSS. However, even when methanogenic activity measurements indicate a severe inhibition, the anaerobic sludge was able to methanise adsorbed LCFA up to 2,000 $\mathrm{mg} \mathrm{COD} / \mathrm{gVSS}$ at a rate of $250 \mathrm{mg} \mathrm{COD} / \mathrm{gVSS}$.d. This evidences that anaerobic consortia remain active while loaded with LCFA. Furthermore, after allowing the depletion of the adsorbed LCFA, the methanogenic activities in the presence of acetate, butyrate and $\mathrm{H}_{2} / \mathrm{CO}_{2}$ were significantly enhanced.

From a practical viewpoint these results represent a challenge for the degradation of effluents with high lipid content. The key seems to be to favour the adsorption of LCFA onto the sludge and to allow the adsorbed substrate to be biodegraded. Then the sludge recovers its activity and a new cycle can start.

\section{Acknowledgements}

The authors acknowledge the Fundação para a Ciência e Tecnologia (FCT) for the financial support given to M. A. Pereira (PRAXIS XXI/BD/20326/99).

\section{References}

Alves, M.M., Bellouti, M., Pereira, M.A., Álvares Pereira, M.R., Mota Vieira, J.A., Novais, J.M. and Mota,

M. (1998). A new method to study interactions between biomass and packing material in anaerobic filters. Biotechnol. Tech., 12(4), 277-283.

Alves, M.M., Mota Vieira, J.A., Álvares Pereira, R.M., Pereira, M.A., Novais, J.M. and Mota, M. (2001). 
Effects of lipids and oleic acid on biomass development in anaerobic fixed bed reactors. Part I: Biofilm growth and activity. Wat. Res., 35(1), 255-263.

Angelidaki, I. and Ahring, B.K. (1992). Effects of free long-chain fatty acids on thermophilic anaerobic digestion. Appl. Microbiol. Biotechnol., 37, 808-812.

Cavaleiro, A.J., Alves, M.M. and Mota, M. (2001). Microbial and operational response of an anaerobic fixed bed digester to oleic acid overloads. Proc. Biochem., 37, 387-394.

Colleran, E., Concannon, F., Goldem, T., Geoghegan, F., Crumlish, B., Killilea, E., Henry, M. and Coates, J. (1992). Use of methanogenic activity tests to characterize anaerobic sludges, screen for anaerobic biodegradability and determine toxicity thresholds against individual anaerobic trophic groups and species. Wat. Sci. Tech., 25(7), 31-40.

Hanaki, K., Matsuo, T. and Nagase, M. (1981). Mechanisms of inhibition caused by long chain fatty acids in anaerobic digestion process. Biotechnol. Bioeng., 23, 1591-1560.

Hwu, C.-S., Tseng, S.-K., Yuan, C.-Y., Kulik, Z. and Lettinga, G. (1998). Biosorption of long-chain fatty acids in UASB treatment process. Wat. Res., 32, 1571-1579.

Pereira, M.A., Mota, M. and Alves, M.M. (2001). Degradation of oleic acid in anaerobic filters: effect of inoculum acclimatization and biomass recirculation. Wat. Environ. Res., 73(5), 612-621.

Pereira, M.A., Pires, O.C., Mota, M. and Alves, M.M. (2002). Anaerobic degradation of oleic acid by suspended and granular sludge: identification of palmitic acid as a key intermediate. Wat. Sci. Tech., 45(10), 139-144.

Rinzema, A., Boone, M. Van Knippenberg, K. and Lettinga, G. (1994). Bactericidal effect of long chain fatty acids in anaerobic digestion. Wat. Environ. Res., 66, 40-49. 